\title{
The role of erythropoiesis-stimulating agents in contemporary clinical practice
}

\section{Marta Frąckowiak', Tomasz Lewandowski ${ }^{1-3}$}

${ }^{1}$ Radom Oncology Centre

${ }^{2}$ Postgraduate Medical Education Centre

${ }^{3}$ Centre of Oncology in Warsaw

Correspondence:

Marta Frackowiak Radom Oncology Centre 26-600 Radom, ul. Uniwersytecka 6 m.frackowiak@onkologiaradom.pl

Received: 14.01.2018. Accepted: 28.02.2018.

DOI: 10.24292/01.OR.280218 Copyright $\odot$ Medical Education. All rights reserved.

\section{ABSTRACT}

Anaemia is one of the most significant factors that lead to deteriorated quality of life and limited therapeutic possibilities in cancer patients. When treating chronic anaemia associated with a neoplastic disease, one should consider RBC transfusion or the use of recombinant human erythropoiesis-stimulating agents (ESA).

In 2007, following the golden era of ESA at the beginning of the $21^{\text {st }}$ century, the American Food and Drug Administration (FDA) issued a number of warnings related to the use of ESAs. They concerned, i.e., the increased risk of cancer progression, probability of venous thromboembolism (VTE), and reduced overall survival times. That has led to a decrease in the use of erythropoiesis-stimulating agents in clinical practice. Results of the most recent studies and meta-analyses indicate the possibility of using ESA in patients undergoing palliative myelosuppressive chemotherapy, with haemoglobin levels $<10 \mathrm{~g} / \mathrm{dl}$, and without absolute iron deficiency, in order to avoid red cell concentrate transfusions, and with the hope to improve the patient's quality of life.

Key words: cancer-induced anaemia, erythropoiesis-stimulating agents, ESA use guidelines 


\section{INTRODUCTION}

Anaemia is one of the most significant factors that lead to deteriorated quality of life and limited therapeutic possibilities in cancer patients. Incidence of anaemia in cancer patients ranges from $40 \%$ in the case of solid tumours, chiefly lung cancer and gynaecological tumours, up to nearly $100 \%$ in hematologic malignancies [8].

Anti-cancer treatment and cytokines induced by the chronic inflammatory process inhibit erythropoiesis by means of reducing erythropoietin production, amongst other mechanisms involved $[1,2]$. Other factors that may trigger anaemia and affect its intensity include: congenital red cell structure and function abnormalities, malnutrition, iron, vitamin $\mathrm{B}_{12}$ and folic acid deficiencies, elderly age, haemorrhages, hypersplenism, haemolysis, secondary bone marrow involvement, kidney diseases and radiotherapy $[1,2]$. Additionally, mutations or therapy-induced inhibition of the intracellular c-kit domain may partially be to blame for reduced erythropoiesis. It is caused by a reduction in the c-kit-dependent phosphorylation and in the intracellular interaction between c-kit and the tyrosine kinase domain of the erythropoietin receptor [1].

Physiological consequences of low haemoglobin levels are similar irrespectively of their origin, whereas their therapeutic management differs, depending on the degree of anaemia, intensity of the symptoms involved, and the patient's clinical situation, including the type of anti-cancer therapy applied, the goal of treatment, and presence of comorbidities.

Having eliminated causes of anaemia other than chronic disease-induced anaemia, one should consider a red cell concentrate transfusion or use of ESA. Transfusion of red cell concentrates is associated with risks such as hypervolemia, transmission of viral or bacterial infections, iron overload, and transfusion-related acute lung injury (TRALI), which is why clinicians have been greatly interested in using ESA.

\section{RECOMBINANT ERYTHROPOIESIS-STIMULATING AGENTS}

Erythropoietin (EPO) is a glycoprotein peptide hormone, secreted in the human body primarily by the kidneys (ca. $80 \%$ of EPO synthesis), and to a lesser degree by the liver. Based on a closed-loop feedback mechanism, hormone expression depends on tissue hypoxia, which stimulates renal cells to produce EPO. Once the erythrocyte count increases, and tissue oxygenation rises, hormone production drops. Erythropoietin is active upon bind- ing with the specific transmembrane erythropoietin receptor (EpoR). Recombinant erythropoietin-stimulating agents behave just like the human erythropoietin protein.

There are 3 products available on the market: epoetin $a$, epoetin $\beta$ and darbepoetin $\alpha$. The first 2 are analogues of their human counterparts, while the third one differs from them in that it contains additional glycosylation sites, and thus has a longer half-life.

ESAs are indicated in the treatment of anaemia resulting from a chronic kidney disease, chemotherapy and some HIV treatment methods. They are also used in order to lower the number of blood transfusions during and after certain surgical procedures.

\section{CLINICAL USE OF ESA - CONTROVERSIES}

Before 2006, ESA use in anaemic patients undergoing anti-cancer treatment was considered safe and efficacious.

In 2003, a randomized controlled trial was carried out in 351 patients with head and neck tumours, whose baseline haemoglobin levels were below $12 \mathrm{~g} / \mathrm{l}$ in women and below $13 \mathrm{~g} / \mathrm{l}$ in male subjects. The patients received radiotherapy, and were randomized to the subcutaneous placebo arm $(n=171)$ or to the epoetin $\beta$ arm ( $n=180)$, administered 3 times a week, before and during irradiation. Progression-free survival and overall survival times were assessed. In the epoetin $\beta$ group, overall survival time was shorter, amounting to 605 days as compared to 928 days in the placebo group ( $p=0.02$ ), and locoregional progression was faster by nearly 2 months ( $p=0.007$ ). However, those critical of the study design pointed out the high baseline haemoglobin levels at which patients were started on EPO [5].

The unfavourable effect of ESA was also observed in a study of 2005 , conducted by Leyland-Johnes et al. The impact of epoetin a on patient survival and quality of life was compared to placebo in female patients with metastatic breast cancer, undergoing first-line chemotherapy, with haemoglobin levels ranging from 12 to $14 \mathrm{~g} / \mathrm{dl}$. 12-month overall survival (OS) was the primary endpoint of the study, and it amounted to $70 \%$ in the epoetin a group, and $76 \%$ in the placebo arm $(p=0.01)$ [6]. In early 2007, the American Food and Drug Administration (FDA) issued a number of warnings concerning ESAs as potential risk factors behind tumour progression, development of venous thromboembolism (VTE), and reduced patient survival. It all led to a considerable decrease in ESA use in the years 2007-2008. Interestingly enough, blood transfusion numbers did not go up [10,12]. 


\section{REVIEW OF THE MOST RECENT STUDIES}

In 2013, Grant et al. updated the 2006 meta-analysis, presenting the benefits and risks related to the use of erythropoietin-stimulating agents as well as strategies other than ESA in the treatment of anaemia in patients subjected to chemotherapy and radiotherapy for malignancies [4]. Amongst other factors, duration of therapy and different baseline haemoglobin levels were taken into consideration. 59 clinical studies were analysed in total. ESAs were found to decrease the need for transfusion (RR $0.58 ; 95 \% \mathrm{Cl} 0.53-0.64$ ), and increase the risk of VTE (RR 1.51; $95 \% \mathrm{Cl} 1.30-1.74)$. During the period of ESA use, mortality was higher ( $\mathrm{HR} 1.17 ; 95 \% \mathrm{Cl} 1.04-1.31$ ). No differences were observed between epoetin and darbepoetin. Adverse events, including fatal thromboembolic complications, were less frequent, when ESA treatment was initiated at haemoglobin values $<10 \mathrm{~g} / \mathrm{dl}$. The obtained data did not enable the determination of the optimum treatment duration, though.

Cochrane review, published in 2004 for the first time, and updated in 2012, was aimed at evaluating the impact of ESA on the prevention or treatment of anaemia in cancer patients [3]. Data of over 19 thousand patients, involved in studies conducted between 1985 and November 2011, was analysed. The results were similar to those rendered in Grant's meta-analysis. ESA use was found to significantly reduce relative risk of red blood cell transfusion (RR 0.65; 95\% C 0.62-0.68). Patients who were treated with ESAs would receive, on average, one unit of blood less than those in the control arm. On the other hand, ESA use was associated with an increase in the risk of thromboembolic complications and mortality during the treatment period ( $\mathrm{HR} 1.17 ; 95 \% \mathrm{Cl} 1.06-1.29)$ as well as with reduced overall survival times (HR 1.05; 95\% Cl 1.00-1.11). Additionally, convincing evidence was collected regarding ESAs as agents that improve the quality of life, but increase the risk of hypertension [3].

In 2016, the above mentioned author, Leyland-Johnes, and collaborators, published the results of a yet another study looking into the use of epoetin a in metastatic breast cancer patients, but that time, one of the inclusion criteria was haemoglobin level $\leq 11.0 \mathrm{~g} /$ $\mathrm{dl}$. The primary endpoint of the study was progression-free survival (PFS), and the secondary endpoints included overall survival, time to tumour progression, overall response rate, number of RBC transfusions, and thrombotic vascular events. 2098 patients were randomly assigned to epoetin a or best standard of care. Median PFS was the same for both groups, amounting to 7.4 months, based on investigator assessment, and 7.6 months based on independent review (HR 1.089; 95\% Cl 0.988-1.200), while median overall survival was 17.2 months in the epoetin arm, and 17.4 months in the control arm (HR 1.057; 95\% Cl 0.949-1.117). Transfusions were reported in $5.8 \%$ of patients as compared with $11.4 \%$ of patients, respectively ( $<0.001)$, and thrombotic vascular events affected $2.8 \%$ of the epoetin patients as compared to $1.4 \%$ of the patients in the best standard of care group ( $p=0.038$ ). The authors concluded that transfusion should thus be the management of choice in the treatment of anaemia in that population of patients [7].

An interesting issue to consider is the relationship between ESA-related complications and the type of cancer involved. That subject matter is explored by a meta-analysis of 2016, conducted by Sukrithan and Gralla, which involved patients suffering from head and neck tumours, lung, breast and pelvic cancers. Despite a comparable risk of thrombosis (OR 1.93) in all 4 tumour types, there were significant differences in terms of survival rates. In the case of breast cancer as well as the head and neck tumours, survival time was reduced in the ESA groups, with the OR of 1.2 and 1.23, respectively. No such correlation was observed for other tumour types. It would appear that the differences in survival times are not associated with thrombotic complications, as the risk of thrombotic events was the same in all of the tumour types under analysis. The above findings indicate that in some tumours ESAs may play a role in tumour promotion [11].

TABLE 1.

ESA-related complications and types of cancer.

\begin{tabular}{|l|l|c|c|c|}
\hline & & $\begin{array}{c}\text { Studies } \\
\text { (patients) }\end{array}$ & OR (95\%CI) & $p$ \\
\hline $\begin{array}{l}\text { Thrombo- } \\
\text { embolic } \\
\text { incidents }\end{array}$ & total & $27(8259)$ & $1.93(1.6-2.34)$ & $<0.01$ \\
\hline & $\begin{array}{l}\text { head and neck } \\
\text { tumours }\end{array}$ & $3(794)$ & $2.17(0.89-5.3)$ & 0.09 \\
\hline & breast cancer & $8(4518)$ & $1.94(1.46-2.57)$ & $<0.01$ \\
\hline & lung cancer & $7(1747)$ & $1.82(1.35-2.48)$ & $<0.01$ \\
\hline $\begin{array}{l}\text { Survival } \\
\text { time }\end{array}$ & pelvic tumours & $9(1200)$ & $2.24(1.19-4.21)$ & 0.01 \\
\hline & total & $32(9692)$ & $1.09(0.98-1.2)$ & 0.12 \\
\hline & $\begin{array}{l}\text { head and neck } \\
\text { tumours }\end{array}$ & $5(1397)$ & $1.23(0.98-1.53)$ & 0.07 \\
\hline & breast cancer & $9(4713)$ & $1.20(1.03-1.39)$ & 0.02 \\
\hline & lung cancer & $10(2417)$ & $0.94(0.73-1.2)$ & 0.6 \\
\hline & pelvic tumours & $8(1165)$ & $1.06(0.85-1.33)$ & 0.6 \\
\hline
\end{tabular}

\section{CURRENT RECOMMENDATIONS}

In 2010, the American Society of Clinical Oncology and the American Society of Haematology updated their guidelines on ESA use in cancer patients. They have been binding and valid to this date.

In accordance with the guidelines, epoetin and darbepoetin agents are considered equivalent with respect to effectiveness and safety. 
Their use may be considered in anaemic patients receiving chemotherapy, with haemoglobin levels $<10 \mathrm{~g} / \mathrm{dl}$, in order to reduce the number of necessary transfusions, and to improve the patients' quality of life. If there is no response to treatment, continuation of epoetin or darbepoetin therapy beyond 6-8 weeks does not appear to be beneficial. Non-responders should be examined with respect to primary disease progression, iron deficiency and other causes of anaemia. Recombinant erythropoiesis-stimulating agents should be administered at the lowest dose necessary to reach a haemoglobin level that prevents transfusion. One should avoid administering ESAs in cancer patients who do not receive concurrent chemotherapy, except for the low-risk myelodysplastic syndromes. One should be cautious, when administering ESAs together with chemotherapeutics in diseases associated with an increased risk of thromboembolic complications [9].

\section{SUMMARY}

Based on the most recent studies and meta-analyses, the 2010 guidelines of the American Society of Clinical Oncology and the American Society of Haematology are considered valid.
Who may benefit most from ESA therapy? The treatment should be considered in patients receiving palliative myelosuppressive chemotherapy, with haemoglobin levels $<10 \mathrm{~g} / \mathrm{dl}$, and without absolute iron deficiency.

Several problems have remained unsolved, though. There have been no clinical studies looking into the management of cancer patients with thrombosis, in whom ESA use is considered. Further studies are also needed into the role of primary VTE prevention in high-risk patients who are candidates for ESA therapy.

To date, there have been no study results available that would facilitate the choice of an optimum treatment of anaemia related to targeted therapies involving agents such as sunitinib, erlotin$i b$, trastuzumab and imatinib. The safety of ESA use in those cases has not been established yet. Further studies are also required into the cellular and molecular mechanisms as well as the signalling pathways behind the impact of recombinant erythropoiesis-stimulating agents on thrombogenesis and their potential impact on tumour growth [3].

References

1. Gilreath JA, Stenehjem DD, Rodgers GM. Diagnosis and treatment of cancer-related anemia. Am J Hematol 2014; 89(2): 203-212. DOI: 10.1002/ ajh.23628.

2. Steensma DP. Is anemia of cancer different from chemotherapy-induced anemia? J Clin Oncol 2008; 26(7): 1022-1024.

3. Tonia T, Mettler A, Robert N et al. Erythropoietin or darbepoetin for patients with cancer. Cochrane Database Syst. Rev. 2012; 12: CD003407. DOI: 10.1002/14651858.CD003407.pub5.

4. Grant MD, Piper M, Bohlius J et al. Epoetin and Darbepoetin for Managing Anemia in Patients Undergoing Cancer Treatment: Comparative Effectiveness Update. AHRQ Comparative Effectiveness Reviews 2013; Report No. 13-EHC077-EF.

5. Henke M, Laszig R, Rübe $C$ et al. Erythropoietin to treat head and neck cancer patients with anaemia undergoing radiotherapy: randomised, double-blind, placebo-controlled trial. Lancet 2003; 362(9392): 1255-1260.

6. Leyland-Jones B, Semiglazov V, Pawlicki M et al. Maintaining normal hemoglobin levels with epoetin alfa in mainly nonanemic patients with metastatic breast cancer receiving first-line chemotherapy: a survival study. J Clin Oncol 2005; 23(25): 5960-5972.

7. Leyland-Jones B, Bondarenko I, Nemsadze G et al. A Randomized, Open-Label, Multicenter, Phase III Study of Epoetin Alfa Versus Best Standard of Care in Anemic Patients With Metastatic Breast Cancer Receiving Standard Chemotherapy. J Clin Oncol 2016; 34(11): 1197-1207. DOI: 10.1200/ JCO.2015.63.5649.

8. Winczura P, Jassem J. Rekombinowana ludzka erytropoetyna w leczeniu niedokrwistości u chorych na nowotwory: nadzieje i zagrożenia. Onkologia w Praktyce Klinicznej 2007; 3(4): 198-204.

9. Rizzo JD, Brouwers M, Hurley P et al. American Society of Clinical Oncology/American Society of Hematology Clinical Practice Guideline Update on the Use of Epoetin and Darbepoetin in Adult Patients with cancer. J Clin Oncol 2010; 28(33): 4996-5010.

10. Stafkey-Mailey D, Dickson M. Changes in use of erythropoetin-stimulating agents (ESAs) in cancer patients: before and after FDA safety advisories. Meeting Library ACO university. June 2, 2012.

11. Sukrithan V, Gralla RJ. Do risks with the use of erythropoetitin stimulating agents (ESAs) differ by tumor type? Implications concerning survival and thrombosis based on meta-analysis (MA). Meeting Library ACO university. June 6, 2016.

12. Dickinson KM, Sakr BJ. ESA use in women with cancer: Consequences of the 2008 FDA clinical alert. Poster at 2012 ASCO Annual Meeting.

Authors' contributions: Marta Frąckowiak: 70\%; Tomasz Lewandowski: 30\% Conflict of interests: 